\title{
Intussusception of the bowel in adults: two different cases
}

Ergin Arslan', Kasım Çağlayan'1, Mesut Sipahi', Oktay Banlı', Fatma Gündoğdu², Sevinç Șahin ${ }^{3}$

\begin{tabular}{|c|c|}
\hline ABSTRACT & $\begin{array}{l}\text { Intussusception in adults is considered an unusual condition accounting for } 5 \% \text { of all cases of intussusceptions and } \\
\text { almost } 1 \%-5 \% \text { of all cases of bowel obstruction. We present two cases of patients with a complaint of abdominal } \\
\text { discomfort and concomitant vomiting who are } 43 \text { and } 44 \text { years old. lleocecal intussusception was diagnosed by com- } \\
\text { puted tomography. One patient underwent open whereas the other underwent laparoscopic right hemicolectomy } \\
\text { and ileotransversostomy. A histopathological study revealed lipoma in the first case and adenocarcinoma in the } \\
\text { second. We described the diagnosis and treatment of intestinal intussusception in adults. }\end{array}$ \\
\hline & Keywords: Adults, intussusception, diagnosis, treatment \\
\hline
\end{tabular}

\section{INTRODUCTION}

Intussusception is defined as invagination of an intestinal segment with its mesentery as a result of peristalsis into the intestinal lumen. In most cases, the causes of colic intussusception in adults are malignant disease, whereas the causes of small bowel intussusception are frequently benign (lipoma, polyps, adenomas, and Meckel's diverticulum) (1). It was first defined in 1674 by Barbette and Sir Jonathan Hutchinson was the first to operate on a child with intussusception in 1871 (2). Intestinal intussusception in adults is considered as an unusual pathology and represents $5 \%$ of the total cases of intestinal intussusception (children and adults) and $1 \%-5 \%$ of all cases of intestinal obstruction (3). Intussusceptions are classified along with their locations into four categories: enteroenteric, colocolic, ileocolic, and ileocecal (4).

Computed tomography (CT) is the most sensitive diagnostic method for intussusceptions. All researchers report that surgery is the most effective treatment for adult intussusceptions (5). We described the diagnosis and treatment of intestinal intussusception in adults.

\section{CASE PRESENTATIONS}

Cite this paper as: Arslan E, Çağlayan K, Sipahi M, Banlı 0, Gündoğdu F, Şahin S. Intussusception of the bowel in adults: two different cases. Turk J Surg 2017; 33: 217-219.

'Department of General Surgery, Bozok University School of Medicine, Yozgat, Turkey

2Department of Radiology, Bozok University School of Medicine, Yozgat, Turkey

${ }^{3}$ Department of Pathology, Bozok University School of Medicine, Yozgat, Turkey

\section{Address for Correspondence} Ergin Arslan e-mail: ergnrsln@hotmail.com

Received: 20.11.2014

Accepted: 12.02.2015

Available Online Date: 14.07.2015

OCopyright 2017

by Turkish Surgical Association

Available online at

www.turkjsurg.com

\section{Case 1}

A 44-year-old man was admitted to the emergency department with three months history of intermittent lower right abdominal pain and nausea. He also had a history of obstipation and constipation. These symptoms worsened over the past three days. He had no operation history. There was no familial history of any disease. On physical examination, the abdomen was minimally distended and tender. In the right lower quadrant, an approximately $8 \mathrm{~cm}$ diameter mass was palpated with a deep palpation. The results of routine laboratory examinations were within the normal limit. The abdominal X-ray showed dilated loops of the small intestine, which was indicated as an obstructive pattern. After resuscitation, a CT scan was performed, which showed dilatation of small intestine because of ileocecal invagination. On exploratory laparotomy, an ileocecal intussusception was found (Figure 1). After manual reduction, a $6-\mathrm{cm}$ diameter properly limited mass was palpated in the cecum (Figure 2). Right hemicolectomy and endto-side ileotransversostomy were performed. The postoperative duration was uneventful, and he was discharged seven days after surgery. On the gross and histopathological examination of the resected cecum, a well delineated and $6.2 \mathrm{~cm} \times 5.1 \mathrm{~cm} \times 4.4 \mathrm{~cm}$ lipomatous neoplasm was detected.

\section{Case 2}

A 43-year-old man was admitted to the general surgery clinic with a diagnosis of intussusception from a gastroenterology outpatient clinic. He had a history of obstipation, constipation, and intermittent right quadrant abdominal pain. There was no weight loss in the patient. The results of routine laboratory examinations were within the normal limit. The abdominal X-ray showed non-dilated loops of the small intestine. Abdominal CT revealed cecum distention and cecal wall thickening, which were suggestive of inflammation in the cecum wall and ileocecal invagination (Figure 3a, b). An intense hypodense appearance was observed in the lumen of the cecum. There was no evidence of complete obstruction 


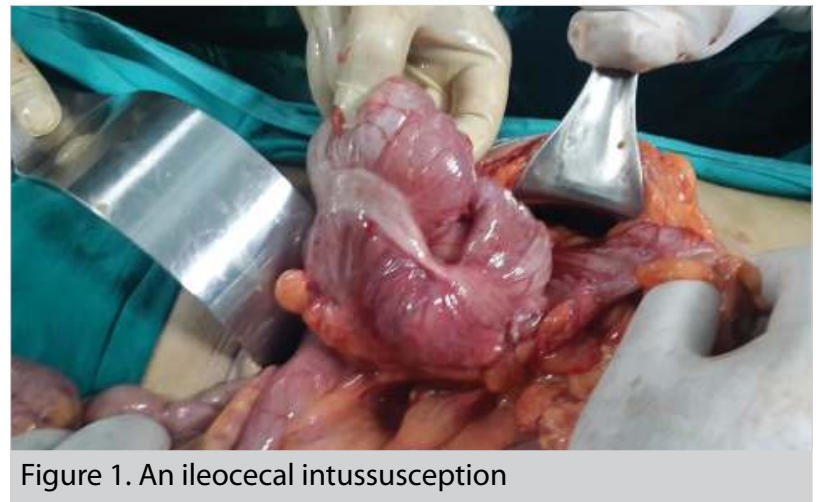

Figure 1. An ileocecal intussusception

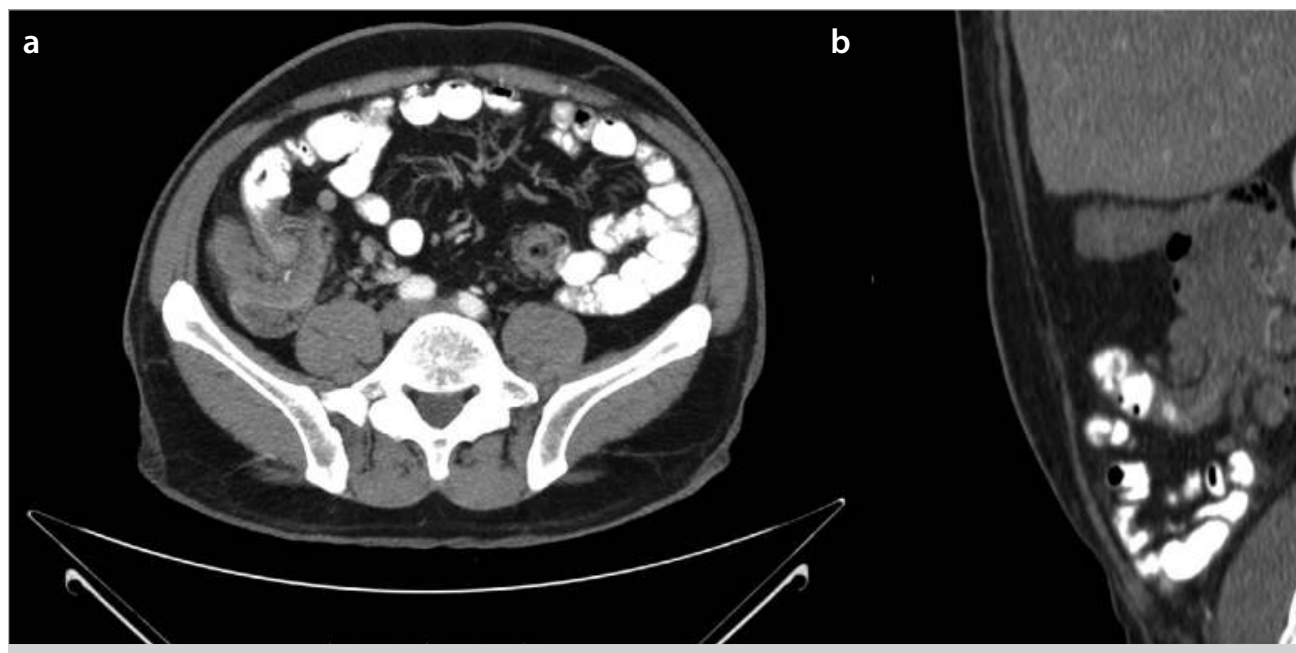

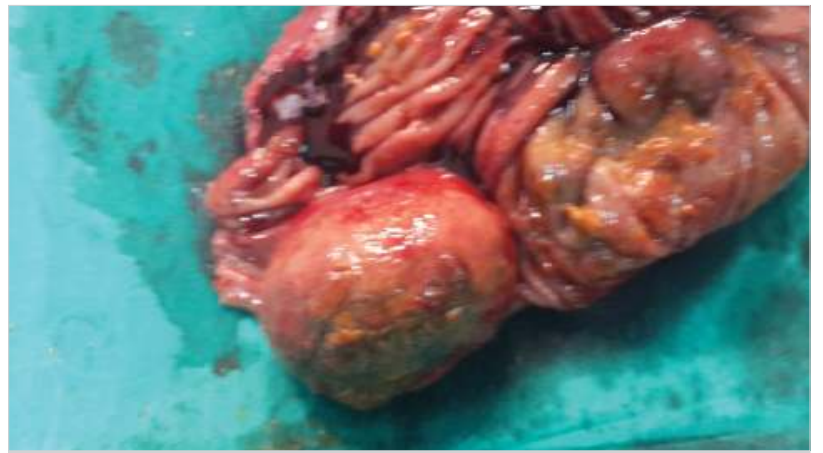

Figure 2. Lipoma causing intussusception

Figure 3. a, b. An ileocecal intussusception on computed tomography examination

in the patient, and colonoscopy was performed. An ulcerated mass in the lumen of the ascending colon and cecum was observed. A biopsy was taken. The biopsy confirmed the diagnosis of adenocarcinoma. Laparoscopic right hemicolectomy and ileotransversostomy was performed. The postoperative duration was uneventful, and he was discharged seven days after surgery. On the gross and histopathological examination of the resected cecum and ascending colon, a $6.5 \mathrm{~cm} \times 4.8 \mathrm{~cm}$ $\times 2.2 \mathrm{~cm}$ tumoral lesion with irregular margins and four positive lymph nodes were detected. Mucinous adenocarcinoma was reported. The patient was classified as T3N2a (according to TNM classification stage $3 \mathrm{~B}$ ) and adjuvant chemotherapy was administered.

\section{DISCUSSION}

Abdominal distension and tenderness are common physical findings in intussusception. Abdominal mass, tenderness, and hemoglobin positive stools are the classic triad of intussusception, but these are rarely found in adults. Blood loss or a palpable mass are present in a minority of the cases. Symptoms can be acute, intermittent, or chronic. In this study, the findings of intermittent obstruction were present in both cases. The clinical presentation in adult intussusceptions is often chronic, and most patients present with non-specific symptoms that are suggestive of intestinal obstruction. The symptoms in cases of adult intussusception are so non-specific that a clinical diagnosis beyond bowel obstruction is rarely made before surgery (6).
Obtaining the complete history and performing a physical ex amination are important. In the diagnosis of intussusception in adults, imaging modalities are essential. Although abdominal ultrasound and double-contrast radiographs could be used, abdominal CT is the most commonly used imaging modality because of the diagnostic appearance (7). On CT, intussusception appears as a "sausage-shaped" mass in the longitudinal axis and as a "target" mass in the transverse axis. Also, a thickened bowel wall with loss of facial plan and a reniform (pseudokidney) or thick-walled bilobulated image may be suggestive of vascular failure and helps in the decision of emergency surgery. Ischemic necrosis of the affected bowel segment is very important in selecting the optimal treatment decisions. Although it may be easily diagnosed with $\mathrm{CT}$ and magnetic resonance imaging, the primary reason is to reveal the condition of the intestines and the affected bowel segment (8).

Barbiera et al. (9) did not recommend hydrostatic reduction of intussusception because of the high likelihood of malignancy in adults, and instead, they recommended laparotomy. Authors suggest that surgical resection without reduction should be the standard treatment in adults because approximately $50 \%$ of adult intussusceptions are associated with malignant lesions. Simple reduction is recommended only in idiopathic intussusceptions where no pathological underlying lesion is present (10). The choice of using a laparoscopic or open procedure depends on the clinical condition of the patient and, in particular, the experience of surgeon with laparoscopic procedures.

\section{CONCLUSION}

In adults, intestinal intussusception represents a rare cause of intestinal obstruction. Clinical and paraclinical diagnostic 
methods used in intestinal intussusception contribute to act quickly and perform limited intestinal resections. Tumors of the terminal ileum, cecum, and ascending colon represent possible causes of progressive intestinal intussusception.

Informed Consent: Written informed consent was obtained from patients who participated in this case.

Peer-review: Externally peer-reviewed.

Author Contributions: Concept - E.A.; Design - E.A., K.Ç.; Supervision K.Ç., M.S., O.B.; Data Collection and/or Processing - E.A., F.G., S.Ş.; Analysis and/or Interpretation - E.A., K.Ç.; Literature Review - E.A., F.G., S.Ş.; Writer - E.A., K.Ç.; Critical Review - K.Ç., O.B.

Conflict of Interest: No conflict of interest was declared by the authors.

Financial Disclosure: The authors declared that this study has received no financial support.

\section{REFERENCES}

1. Kim YH, Blake MA, Harisinghani MG, Archer-Arroyo K, Hahn PF, Pitman MB, et al. Adult intestinal intussuseption: $C T$ appearances and identification of a causative lead point. Radiographics 2006; 26: 733-744. [CrossRef]
2. Hutchinson $\mathrm{H}$, Hutchinson J. Jonathan Hutchinson, life and letters. 1st ed. London: Wm Heinemann Medical Books, 1946.

3. Vizeteu R, Damian M. Intussusception in adult-a rare case. Chirurgia (Bucur) 2011; 106: 119-120.

4. Nagorney DM, Sarr MG, Mcllrath DC. Surgical management of intussusception in the adult. Ann Surg 1981; 193: 230-236. [CrossRef]

5. Erkan N, Haciyanli M, Yildirim M, Sayhan H, Vardar E, Polat AF. Intussusception in adults: an unusual and challenging condition for surgeons. Int J Colorectal Dis 2005; 20: 452-456. [CrossRef]

6. Lianos G, Xeropotamos N, Balı C, Baltogiannis G, Ignatiadou E. Adult bowel intussusception: presentation, location, etiology, diagnosis and treatment. G Chir 2013; 34: 280-283.

7. Israelit SH, Brook OR, Abboua B, Molner R, Dueka SD, Krausz MM. Intestinal intussusception in elderly patients. Maturitas 2009; 62: 124-126. [CrossRef]

8. Park SB, Ha HK, Kim AY, Lee SS, Kim HJ, Park BJ, et al. The diagnostic role of abdominal $C T$ imaging findings in adults intussusception: focused on the vascular compromise. Eur J Radiol 2007; 62: 406-415. [CrossRef]

9. Barbiera F, Cusma S, Di Giacomo D, Finazzo M, Lo Casto A, Pardo S. Adult intestinal intussusception: comparison between $C T$ features and surgical findings. Radiol Med 2001; 102: 37- 42.

10. Azar T, Berger DL. Adult intussusception. Ann Surg 1997; 226: 134-138. [CrossRef] 